\title{
NIVEL DE PURIFICACIÓN DEL AGUA UTILIZADA EN CLINICAS ODONTOLOGICAS UNIVERSITARIAS
}

\author{
Level of water Purification that used the Odontological Clinics University \\ *Tulio Arnaldo Bueso, **Ana Gabriela Cálix Zúniga, **Elonia Andrea Altamirano, \\ ${ }^{* *}$ Jaime Alexis Padilla, **Lizbeth Deyanira Pineda, **Luis Gustavo Barahona.
}

\section{RESUMEN}

Las aguas que se utilizan en las clínicas odontológicas deberían estar libres de contaminantes y aceites, para asegurar la calidad en los trabajos realizados. Objetivo: Determinar el contaminante en el agua del sistema de las sillas odontológicas en la UNAH-VS. Materiales y métodos: Estudio transversal, cualitativo y cuantitativo, realizado del 18 de marzo al 4 de abril 2014. Exámenes realizados con la ayuda de un laboratorio privado mediante técnicas de recolección de aguas, utilizando previamente métodos de asepsias para eliminar todo microorganismo proveniente del exterior y no del agua específicamente del grifo, mangueras y ozonificador para mayor certeza del estudio. Las muestras fueron tomadas en el lavador de la clínica grande de la facultad de odontología, ozonificador colocado arriba del mismo y silla odontológica contigua al mismo lavador. Resultados: Los exámenes demostraron que el agua del grifo contiene $47 \%$ de recuento total bacteriano y $86.13 \%$ de dureza; en el ozonificador se encontró $15 \%$ de recuento total bacteriano y $81.17 \%$ de dureza total y el agua de la silla odontológica refleja $100 \%$ en recuento total bacteriano y $83.95 \%$ de dureza total del agua. Conclusiones: El grado de conta-

*Catedrático de Metodología de la investigación en la Carrera de Odontología de la UNAH-VS.

**Estudiantes de la asignatura de Metodología de la investigación de la Carrera de Odontología UNAH-VS.

Dirigir correspondencia a: tuliobueso@yahoo.com minación del agua de las clínicas odontológicas es mayor cuando sale por las mangueras de las sillas odontológicas, la cual va directamente a la boca del paciente. El ozonificador realiza un trabajo eficiente al reducir la dureza del agua así como también el recuento bacteriano.

\section{PALABRAS CLAVE}

Dureza, bacterias, grasas y aceites.

\section{ABSTRACT}

The water used in dental clinics should be free of contaminants and oils to ensure quality in the work. Objective: To determine the contaminant in the water system of dental chairs in the UNAH-VS. Materials and methods: Cross-sectional, qualitative and quantitative study, conducted from 18 March to 4 April 2014 Examinations with the help of a private laboratory using water harvesting techniques, using methods previously asepsis to remove all microorganisms from abroad and not specifically tap water, ozonator hose and for greater certainty of the study. Samples were taken in the scrubber large clinical faculty of dentistry, ozone generator placed above it and at the same dental chair next lavador. Resultados: Tests showed that tap water contains $47 \%$ of total bacterial count and $86.13 \%$ hardness; in the ozone generator $15 \%$ of total bacterial count and $81.17 \%$ total water hardness and the dental chair reflects $100 \%$ total bacterial 
count and $83.95 \%$ of total water hardness encountered. Conclusions: The degree of water pollution from dental clinics is greater when headed hoses dental chairs, which goes directly to the patient's mouth. The ozone generator makes efficient work by reducing water hardness as well as bacterial count.

\section{KEYWORDS}

Hardness, bacteria, fats and oils.

\section{INTRODUCCIÓN}

Las aguas que se utilizan en las clínicas odontológicas deberían estar libres de contaminantes y aceites, para asegurar la calidad en los trabajos realizados. La organización para la seguridad y los procedimientos de asepsis (OSAP) apremia a los dentistas para que tomen las medidas pertinentes que mejoren la calidad del agua empleada durante el tratamiento dental. ${ }^{(1)}$

Los problemas de las infecciones dependen del tipo de patógeno, el modo como se transfiere, dosis o concentración de patógenos, persistencia de los microorganismos y la resistencia de la persona infecta$\mathrm{da}^{(2)}$

Los coliformes totales son las Enterobacteriaceae lactosa-positivas y constituyen un grupo que se definen más por las pruebas usadas para su aislamiento que por criterios taxonómicos que pueden influir en gran parte en la salud.

La mayoría de los microorganismos patógenos contenidos en el agua son eliminados en las primeras etapas del tratamiento para la purificación del agua. No obstante, la de- sinfección del agua es necesaria como uno uno de los pasos últimos para prevenir que el agua potable sea dañina para nuestra salud. ${ }^{(3)}$

La importancia del uso del ozono es el recordar que la utilización de este compuesto no produce en el agua aumento en el contenido de sales inorgánicas ni subproductos nocivos. En definitiva, podemos afirmar que el ozono realiza las siguientes funciones en el agua: degradación de sustancias orgánicas, desinfección, inactivación de los virus, mejora sustanciosa de sabores y olores, eliminación de olores extraños, eliminación de las sales de hierro y manganeso, floculación de materias en suspensión, eliminación de sustancias tóxicas, desestabilización de materias coloidales. ${ }^{(4)}$

Con respecto a la microbiología del agua, dentro del grupo de coliformes totales se encuentran coliformes fecales, que comprenden principalmente Escherichia coli y algunas cepas de Enterobacter y KlebsieIla. ${ }^{(5)}$

La Legionella pneumophila apareció en el ojo público cuando, en 1976, hubo un brote epidémico en una convención de la Legión Americana. Producto de estas surge la legionelosis que es una enfermedad bacteriana de origen ambiental que suele presentar dos formas clínicas diferenciadas: la infección pulmonar o «Enfermedad del legionario» y la forma no neumónica conocida como «Fiebre de Pontiac». La infección por Legionella pneumophila puede ser adquirida en dos ámbitos: el comunitario y el hospitalario. En ambos casos, la enfer- 
medad, puede estar asociada a varios tipos de instalaciones, equipos $o$ edificios. Pueden presentarse en forma de brotes y casos aislados o esporádicos..$^{(6,7)}$

El agua descrita como "dura" significa que es alta en minerales disueltos, específicamente calcio y magnesio. ${ }^{(8-9)}$ El objetivo fue determinar el contaminante en el agua del sistema de las sillas odontológicas en la UNAH-VS.

\section{METODOLOGIA}

Los estudios del agua realizados en la instalación de la clínica, de la facultad odontológica de la UNAH-VS, San Pedro Sula, Cortes fueron cuantitativos y cualitativos. Ya que se hicieron exámenes en las muestras que fueron tomadas en el agua del lavador, agua directamente del ozonificador y el agua de uso en la silla odontológica directamente de la manguera triple, antes de tomar cada muestra se realizó la limpieza del área de la cual se tomaron las muestras y se colocaron en botes estériles con la ayuda del personal del laboratorio privado.

Se buscó si existe la presencia de coliformes totales, coliformes fecales grasas/aceites, se realizó también un recuento bacteriano y la dureza total del agua de cada una de las muestras tomadas, en el examen se detalla la cantidad exacta que existe en cada muestra y en este artículo se especificó datos importantes de cada uno de ellos.

El diseño implementado es el transversal ya que se reunieron los datos de los exámenes realizados en un solo periodo del tiempo, el examen del recuento total bacteriano y el de la dureza ocurrió entre el 2014/03/18 al 2014/03/21 y el examen de coliformes totales, coliformes fecales, Legionella pneumophila, grasa y aceites se dió entre el 2014/03/31 al 2014/04/07.

Los técnicos del laboratorio privado de análisis industrial llegaron a las instalaciones de la Carrera de Odontolgía de la UNAH-VS en un periodo de tiempo para recaudar las muestras y así poder realizar los estudios clínicos sin probabilidad que los resultados estén sesgados.

El sistema de recolección de agua de la facultad de odontología de la UNAH-VS no está regido bajo ningún procedimiento de tratamiento, ya que el agua proviene directamente del proveedor Aguas de San Pedro, S. de R.L. utilizándose el ozonificador que es poca la utilidad para la magnitud de procedimiento de salud que se realizan.

\section{RESULTADOS}

Mediante el análisis del recuento total bacteriano y dureza realizado, señalamos los principales hallazgos entre los que destacan la disminución de la dureza del agua después de pasar por el proceso de ozonificación que se realiza en las clínicas odontológicas de la UNAH-VS, mostrando la eficiencia del ozonificador. Además, el recuento total bacteriano presente en el análisis nos da como resultado que después del proceso de ozonificación el número de bacterias se incrementa al pasar por la manguera de la silla, el cual presenta $100 \%$ de bacterias. (Ver gráfico). 
Gráfico $\mathrm{N}^{\circ}$ 1: Resultados del paso del agua del grifo hasta la silla dental

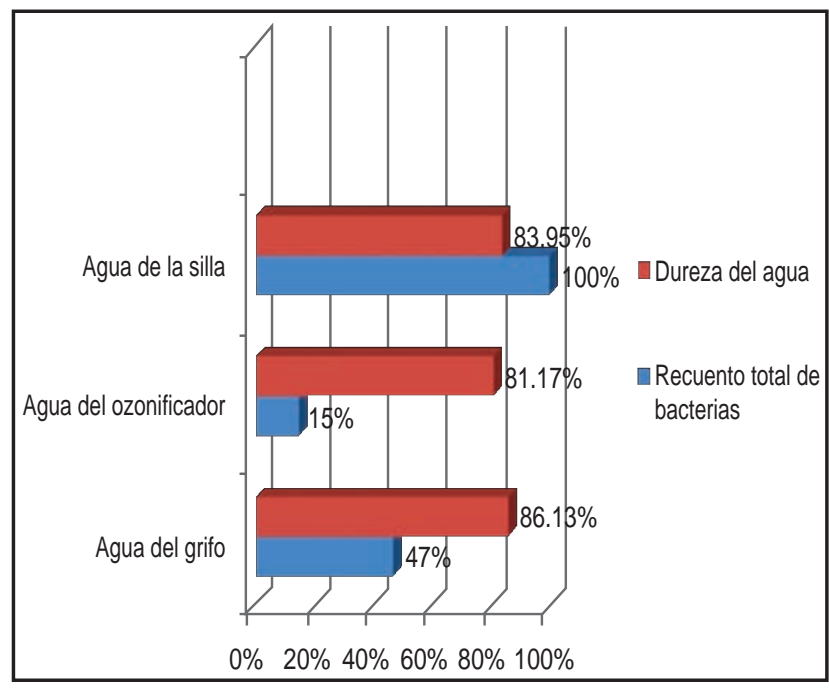

Se observa que al pasar el agua por el ozonificador disminuye el porcentaje de bacterias, pero al llegar a las mangueras de las sillas aumenta al $100 \%$ y la dureza disminuye en el ozonificador pero aumenta en la silla.

Se encontró coliformes totales, fecales, Legionella pneumophila, en el agua del grifo, del ozonificador y de las mangueras de las sillas odontológicas. El análisis de aceites lo encontramos con un valor de $4.75 \%$ en el agua que sale de la manguera triple de la silla odontológica. (Ver gráfico $\mathrm{N}^{\circ} 2$ ).

Gráfico № 2: Informe de resultados de ensayo coliformes totales, legionella pneumophila, grasas y aceites

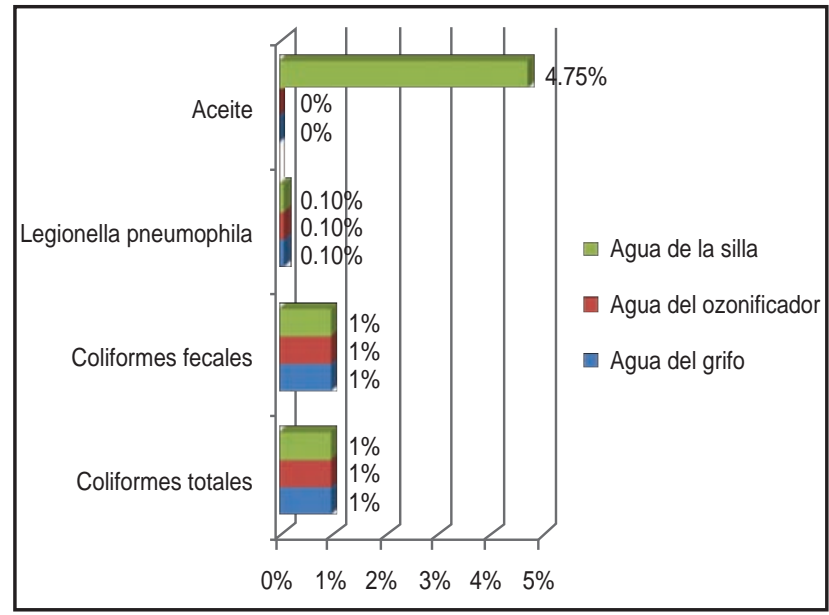

Se observa que en el agua de las mangueras de las sillas se presento $4.75 \%$ de aceite.

\section{DISCUSIÓN}

El nivel de purificación del agua utilizada en las clínicas odontológicas de la UNAH-VS es adecuado a las normas ya que como pudimos observar el ozonificador si cumple su función antes de ingresar a las mangueras de los sillones pero al entrar a las mangueras este se contamina y pierde su poder de control bacteriano. Lo que sí se puede considerar es el hecho que solo existe un aparato de ozono el cual no es suficiente para el uso que se maneja en las clínicas; en el agua que corre por las mangueras de los sillones dentales el nivel de purificación es bajo ya que existe la presencia de bacterias, coliformes totales, coliformes fecales, Legionella pneumophila. Es de considerar que en estudios anteriores como el realizado por el Dr. Chris H. Milleri en el cual revela la existencia de la Legionella pneumophila en las mangueras de las unidades dentales es un problema a resolver. ${ }^{(10,11)}$

También es importante hacer constar que el aspecto del agua dura, las grasas y aceites que se encuentran en las mangueras de los sillones es $4.75 \%$, mientras que en el grifo y el ozonificador es nula. El bajo nivel de purificación que existe en el agua utilizada, la abundante cantidad de aceites y bacterias en las mangueras, puede afectar los tratamientos que se realizan en las clínicas y crea la necesidad de buscar soluciones que eviten posibles complicaciones en los tratamientos a realizar. Poniendo en evidencia la necesidad de mantenimiento que deben de tener las aguas de las clínicas odontológicas de la UNAH-VS así como también el mejoramiento de las mangueras de las sillas en las cuales se realizan los procedimientos odontológicos. 
Dependiendo del cuidado, mantenimiento y limpieza del contenedor de suministro y del sistema hidráulico por que pueden fluir microorganismos planctónicos depositándose en el interior de las paredes de los depósitos y las mangueras en forma de lama; iniciando una cadena de eventos que tienen como resultado la formación de microcolonias adherentes entre sí y a las superficies del sistema hidráulico, con el consecuente desarrollo de una matriz o biopelícula potencialmente infecciosa, formada por bacterias englobadas dentro de micro colonias. ${ }^{(12)}$

En una investigación realizada en Zacatecas México, ${ }^{(13)}$ se encontró un número de UFC/mL por encima de lo permitido; corroborando lo anterior en la mayoría de éstas con pruebas confirmativas a coliformes totales y fecales lo cual indica contaminación fecal. Concordando con lo encontrado en las aguas de las clínicas odontológicas de la UNAH-VS.

La Legionella pneumophila u otras especies de Legionella han sido detectadas en el agua de las unidades dentales. La L. pneumophila se descubrió en el agua de alrededor de 42 unidades en 35 lugares de prácti- ca en Austria, en 3 de cada 5 unidades en una clínica hospitalaria dental de Londres. ${ }^{(14)}$ En este estudio, se encontró en el $0.10 \%$ de las aguas del grifo, ozonificador y mangueras del tubo.

Conclusiones; Aunque el porcentaje de bacterias disminuye al pasar el agua por el ozonificador, aumenta en mayor cantidad al pasar por las mangueras de las sillas, afectando la calidad de los trabajos realizados.

Se recomendó a las autoridades de la UNAH-VS realizar cambios de las mangueras de las sillas odontológicas y materiales de aseo para el mantenimiento.

También Informar a los estudiantes con el fin de concientizarlos para que tomen medidas de seguridad con respecto a los procedimientos a efectuar.

Como resultado de la investigación realizada se logró el cambio completo de todas las mangueras de las sillas odontológicas de la Carrea de Odontología de la UNAH-VS, así como también se mejoró el mantenimiento del ozonificador.

\section{BIBLIOGRAFÍA}

1. Osap.org [internet]. Organización para la Seguridad y los Procedimientos de Asepsis [actualizado marzo 2010; consultado 9 abril 2014]. Única publicación. Disponible en: http://www.osap.org/?Int_Mexico_ Trans1.
2. lenntech.es [internet] Water Treatment Solutions. Necesidad desinfección del agua potable [copyright 1998-2014]. Disponible en: http://www.lenntech.es/ procesos/desi nfeccion/necesidad/necesidad-desin feccion-agua.htm\#ixzz2x5 GQIRIW. 
3. centrodeartigos.com [internet]. El agua purificada, Los métodos de purificación, Utiliza, Efectos sobre la salud de beber agua purificada [actualizado 2014: consultado 9 abril 2014]. Disponible en: http://centrodeartigos.com/articulos-util es/article_103424.html.

4. ozono [Internet]. Cartagena Colombia: [consultado 12 abril 2014] Disponible en Ciencia del ozono-el blog de cosemar: http://www.cienciadelozono.es/2011/ 10/que-es-el-agua-ozonizada/.

5. Bailey \& Scott. Diagnostico microbiológico. 12a ed. Argentina, Editorial Médica Panamericana; 2009.

6. salonhogar.com [internet] Disponible en: http://www.salonhogar.com/ciencias/na turaleza/elagua/filtrosdeagua.htm.

7. Daniel c. Harris. Análisis químico cuantitativo. 3ra ed. Barcelona España. Reverte; 2007.

8. nomasaguadura.com [internet] California, EEUU: AQUA GENESIS, Inc.; ¿Por qué el agua dura es un problema? [Consultado 13 abril 2014]

Disponible en: http://nomasaguadura.com/informa cion-tecnica/porque-causa-proble mas-agua-dura.html.
9. Raúl Romero Caballero. Microbiología y parasitología humana.3ra ed. México. Editorial Médica Panamericana; 2007.

10. Ingraham JL, Ingraham CA. Introducción a la microbiología. Editorial Reverte, S.A. Barcelona España; 1998.

11. Millery $\mathrm{ChH}$. Los microbios en el agua de las unidades dentales. Rev Cubana Estomatol 1996;[Citado agosto 21, 2014] 33(3) Disponible en:

http://bvs.sld.cu/revistas/est/vol33_ 3_96/est10396.htm.

12. Miller $\mathrm{CH}$, PaleniCJ. Control de la Infección y Manejo de los Materiales Peligrosos para el Equipo Dental, Mosby Publishing, St. Louis, Missouri, 1994.

13. Muñoz EJJ, Hernández DDR, GA. Calidad bacteriológica del agua de una clínica odontológica rural de la facultad de odontología de la Universidad Autónoma de Zacatecas. Revista ADM 2002;LIX(2):50-57

14. Milleri Chris H.. Los microbios en el agua de las unidades dentales. Rev Cubana Estomatol [revista en la Internet]. 1996 Dic [citado 2014 Oct 20]; 33(3): 140-147. Disponible en: http://scielo.sld.cu/scielo.php?script=s ci_arttext\&pid=S0034-75071996 0003000 10\&lng=es. 